\title{
Evaluation of Effectiveness and Tolerability of Boric Acid in the Treatment of Vaginal Infection with Candida Species
}

\author{
CLAUDIA MEHEDINTU ${ }^{1}$, ELVIRA BRATILA ${ }^{1}$, MONICA CIRSTOIU ${ }^{1}$, AIDA PETCA ${ }^{1}$, LACRAMIOARA AURELIA BRINDUSE ${ }^{1 *}$, \\ COSTIN BERCEANU ${ }^{2}$, RAMONA ILEANA BARAC ${ }^{1}$, CRISTINA VERONICA ANDREESCU ${ }^{1}$ RAZVAN COSMIN PETCA ${ }^{1}$, \\ FLORICA SANDRU'*, OANA MARIA IONESCU ${ }^{1}$ \\ IUniversity of Medicine and Pharmacy Carol Davila, 8 Eroii Sanitari Bvd., 050474, Bucharest, Romania \\ ZUniversity of Medicine and Pharmacy, 2 Petru Rares Str., 200349, Craiova, Romania
}

\begin{abstract}
Vulvovaginal candidiasis is the most prevalent vaginal infection worldwide. Considering the violence of the symptoms that some patients report, the tendency to relapse or of resistance to the azole therapy, and the success reported by some studies in the treatment with boric acid of the vaginal infection with various pathogens, we conducted a prospective study in which we used vaginal boric acid for Candida species infection. The aim of our study was to evaluate the effectiveness and tolerability of boric acid in the treatment of vaginal infection with Candida species. Analysing the data from the satisfaction questionnaire completed by the patients who reached the end of the study showed that our investigational product has a good and very good effectiveness in sterilizing the infection (71\%), being considered by patients to be easily administered (67.7\%), the safety of the product being perceived as good and very good by $93.6 \%$ of them.
\end{abstract}

\section{Keywords: boric acid, vaginitis, Candida spp}

In women of childbearing age, the vaginal ecosystem is dominated by the presence of the Lactobacillus species, whose protective role in the Candida spp infection is due to their lactic acid and toxins production, the interference with the adherence mechanism and the reducing of the energy sources available to fungi [1]. The host factors (local defence mechanisms, genetic polymorphism, glomerulonephritis, antibiotic use, pregnancy, etc.) are responsible for the vaginal colonisation with Candida spp $[2,3]$, and the tendency to relapse or of resistance to the conventional treatment required the search for alternative solutions [4]. Up to $90 \%$ of vaginal candidiasis infection are the result of $\mathrm{C}$. albicans colonisation, and only in $10 \%$ of the cases other species are identified (especially $C$. glabrata, and much less often C. krusei, C. tropicalis, C. kefyr, $C$. africana, $S$. cerevisiae), these last generating symptoms less severe that the classical symptomatology (pruritus, burns, vulvovaginal erythema, odorless leukorrhea) $[2,5]$.

Boron, the element in the Mendeleev's table with the symbol $B$ and the atomic number 5 (atomic mass 10.811 $\mathrm{g} / \mathrm{mol}$ ) is ubiquitous in nature $[6,7]$. Discovered at the beginning of the $19^{\text {th }}$ century, the elemental boron is rarely found as such in nature. More commonly, itis encountered in its bonded forms to sodium and oxygen (organoboric complexes) [6]. At the tissue level (plants, animals or humans) boron is most commonly found as boric acid $\mathrm{B}(\mathrm{OH})_{3}$ (and its borate derivative) (96\%), which by reversibly binding different molecules (nucleotides, carbohydrates, etc.) exerts its antiseptic, bactericide, fungicide, insecticide, herbicide, fertilizer, etc. effects. $[6,7]$. Its antimicrobial properties and the lack of transcutaneous absorption through the intact skin has recommended boric acid as an antiseptic, being used in the topical treatment of the superficial infections since the late $19^{\text {th }}$ century [8]. In gynaecology, the antiseptic and bactericidal effects of boric acid have been demonstrated in numerous studies concerning the effectiveness of its use in the vulvovaginal infections of various etiologies [9-14], being preferred in the treatment of vaginal infections with Candida spp. because it does not induce resistance and its effect is not species-dependent [8].
Approximately $75 \%$ of women experience at least once in their lifetime an episode of vulvovaginal candidiasis (10$25 \%$ of whom develop recurrent disease), while up to $45 \%$ of women have two or more episodes of Candida infection throughout their lives [5]. Considering the violence of the symptoms that some patients report [2], the tendency to relapse or of resistance to the azole therapy [4], and the success reported by some studies in the treatment with boric acid of the vaginal infection with various pathogens [9-14], we conducted a study aiming to evaluate the efficacy of the boric acid vaginal suppositories in patients with documented vaginal infection for Candida spp.

\section{Experimental part \\ Materials and methods}

From August 2016 to January 2017, we conducted a prospective clinical study in the Department of Obstetrics and Gynaecology from the Nicolae Malaxa Clinical Hospital, Bucharest, which aimed to evaluate the effectiveness and tolerability of Flugenil600 vaginal administration in patients with documented vaginal infection for Candida spp., the study being approved by the ethics committee of the aforesaid hospital.

The inclusion criteria for the patients were as follows: age 18 to 45 years, married or in a stable relationship, symptoms and signs characteristic of vulvovaginal candidiasis. Patients' exclusion was made taking into account the following factors: Trichomonas / Gardnerella coinfection, pregnancy, breastfeeding, antibiotic treatment, combined oral contraceptives, corticosteroid therapy, diabetes and autoimmune diseases.

During the selection visit (V1 - initiation / screening), the patients together with the doctor completed a questionnaire containing information on age, marital status, race, medical history, alcohol consumption, smoking, allergies to various foods or medicines, as well as data on the signs and symptoms induced by the presence of Candida spp (pruritus, burning, dysuria, dyspareunia, leukorrhea, vulvar erythema and edema), each item being rated on a scale from 1 to 4 ( $1=$ absent, 2 = slight, $3=$ moderate, 4 = severe). Patients were given a detailed explanation of the study protocol and asked to take part in 
the study. After signing the informed consent, a vaginal discharge specimen was collected for microscopic examination using a sterile speculum, the patients with associated bacterial vaginosis or trichomoniasis infection being excluded. Patients meeting the microscopic criteria were randomized to the second visit and received treatment with Flugenil600 vaginal suppositories, administered intravaginally once a day (in the evening) for 15 days. The third visit was on the fifteenth day $(+/-7$ days) after the end of the treatment, when the patients were again subjected to a microscopic examination of the vaginal discharge and continued using Flugenil600 twice a week for a period of another 8 weeks. The fourth and last visit was the study completion visit when the effectiveness of Flugenil600 was evaluated by performing a final microscopic examination of the vaginal discharge and completing a satisfaction questionnaire.

In the data analysis, we considered the following populations: intent to treat (ITT population - all patients screened to participate in the study), safety population (all patients who received at least one dose of Flugenil600 and who came for at least one visit), and per protocol population (PP population - only patients who followed the entire treatment protocol, came to all visits without major deviations from the protocol). Patients follow-up was done in stages: visit 1 - screening visit (ITT); visit2 - training for daily administration (15 days) of boric acid vaginal suppository, visit 3 - reassessment and continued administration of boric acid vaginal suppositories twice a week for the next 8 w eeks (safety population). At visit 4, at the end of the additional 8 weeks of treatment, the patients in the safety population were re-evaluated on the effectiveness of the treatment based on questionnaire, clinical signs, and microscopic evaluation of the vaginal discharge (PP).

The study results were presented as relative and percentage frequencies for quantitative variables, and as means and standard deviations for quantitative variables. The differences frequencies of the symptoms between the ITT population and the safety population, per protocol population, respectively, were studied using the chi square test. The scores of the vulvovaginitis signs and symptoms were calculated for each visit based on the Likert scale scores, and the ANOVA test was used for repeated measurementin order to compare the baseline and postline results. $p<0.05$ was considered statistically significant. Data analysis was performed by using the SPSS 23.0 software.

\section{Results and discussions}

Of the 71 patients screened according to the eligibility criteria (ITT population) who received microscopic evaluation of the vaginal discharge with the intent of randomization, 7 patients were excluded from the study due to the associated presence of trichomoniasis infection or bacterial vaginosis (screening failure rate of $9.9 \%$ ). The socio-demographic characteristics and the behaviour of the patients included in the study (ITT population) are presented in table 1.
Table 1

PATIENTS CHARACTERISTICS (ITT POPULATION; $n=71$ )

\begin{tabular}{|l|l|}
\hline Characteristics & $\mathrm{N}(\%)$ \\
\hline Age (Mean \pm SD) & $36.3 \pm 7.9$ \\
\hline Residency & $64(90.1)$ \\
Urban & $7(9.9)$ \\
Rural & \\
\hline Marital status & $42(59.2)$ \\
Married & $26(36.6)$ \\
Unmarried & $3(4.2)$ \\
Divorced & \\
\hline Education & $32(45.1)$ \\
Elementary school, 8 classes, high school & $39(54.9)$ \\
University and postgraduate studies & \\
\hline Alcohol users & $7(9.9)$ \\
Frequent & $53(74.6)$ \\
Incidental & $22(31.0)$ \\
\hline Smoking & $4(5.6)$ \\
\hline Food allergies & $2(2.8)$ \\
\hline Drugs allergies & $\mathrm{C}$ \\
\hline
\end{tabular}

The 64 remaining patients were randomized and received Flugenil600, administered once a day intravaginally in the evening for 15 days.

At the third visit two patients did not show up within the set interval and they were excluded from the study. The other 62 patients were clinically reviewed, and a mycological assessment was performed (safety population). Thus 10 more patients were excluded from the study ( 6 for clinical and confirmed mycological infection and 4 for infection without clinical symptoms but with positive mycological examination). The remaining 52 patients received Flugenil600 twice a week for 8 weeks (maintenance treatment).

At visit 4, we found that 2 patients abandoned the study, and of the remaining 50 patients who were present (PP population), 42 patients tested negative at the final mycological control, while 8 patients showed signs of recurrence of symptomatology specific to candidal vaginitis, confirmed by the result of the microscopic examination of the vaginal discharge. No patient discontinued treatment due to adverse effects.

The mycological examination at each visit consisted of a microscopic examination of the vaginal discharge and cultures of vaginal discharge with antifungigram. Upon inclusion in the study, 7 patients were excluded due to coinfection with T. vaginalis / Gardnerella; however, of all the Candida species, the most common encounter was Candida albicans (76.05\%), this species dominating through the entire study period (table 2).

We compared the frequency of signs and symptoms at the inclusion in the study with the results obtained at visit 3 and 4: the most common symptoms at the first visit were pruritus (91.5\%) and burning sensation (87.3\%), while at V 3 and V4 visit the symptomatology was dominated by leukorrhea ( $12.9 \%$ and $12.0 \%$, respectively), pruritus and dyspareunia ( $11.3 \%$ and $10.0 \%$, respectively). Overall, the frequency of all signs and symptoms at the control visits decreased significantly from a statistical point of view compared with V1 ( $<0.001)$ (table 3$)$, the mean scores

\begin{tabular}{|l|l|l|l|l|}
\hline & $\mathrm{V} 1(\mathrm{n}=71)$ & $\mathrm{V} 2(\mathrm{n}=64)$ & $\begin{array}{l}\mathrm{V} 3 \\
(\mathrm{~N}=62)\end{array}$ & V4(n=50) \\
\hline Candida albicans & $\begin{array}{l}54 \\
(76.05 \%)\end{array}$ & $54(84.4 \%)$ & $5(7.7 \%)$ & $7(14.0)$ \\
\hline Candida glabrata & $8(11.27 \%)$ & $8(12.5 \%)$ & $1(1.6 \%)$ & $1(2.0)$ \\
\hline Other Candida species & $2(2.82 \%)$ & $2(3.1 \%)$ & $4(6.4)$ & - \\
\hline Trichomonas+Candida spp & $5(7.04 \%)$ & - & - & - \\
\hline Gardnerella + Candida spp. & $2(2.82 \%)$ & - & - & - \\
\hline
\end{tabular}

Table 2

VAGINAL DISCHARGE MYCOLOGICAL EXAMINATION 


\begin{tabular}{|l|l|l|l|l|l|}
\hline Signs and symptoms & $\begin{array}{l}\text { Before treatment } \\
(\mathrm{n}=71)\end{array}$ & $\mathrm{V3}(\mathrm{n}=62)$ & $\mathrm{p} \mathrm{value}^{8}$ & V4 (n=50) & p value $^{88}$ \\
\hline Leukorrhea & $57(80.3)$ & $8(12.9)$ & $<0.001$ & $6(12.0)$ & $<0.001$ \\
\hline Edema & $51(71.8)$ & $6(9.7)$ & $<0.001$ & $4(8.0)$ & $<0.001$ \\
\hline Rash & $56(78.9)$ & $4(6.4)$ & $<0.001$ & $3(6.0)$ & $<0.001$ \\
\hline Pruritus & $65(91.5)$ & $7(11.3)$ & $<0.001$ & $5(10.0)$ & $<0.001$ \\
\hline Burning sensation & $62(87.3)$ & $4(6.4)$ & $<0.001$ & $3(6.0)$ & $<0.001$ \\
\hline Dysuria & $36(50.7)$ & $2(3.2)$ & $<0.001$ & $1(3.0)$ & $<0.001$ \\
\hline Dyspareunia & $50(70.4)$ & $7(11.3)$ & $<0.001$ & $5(10.0)$ & $<0.001$ \\
\hline
\end{tabular}

${ }^{*}=$ comparing baseline (V1) and primary effects (V3); **= comparing baseline (V1) and

secondary effects (V3)

of signs and symptoms significantly decreasing during treatment at the PP population.

Centralizing data from the satisfaction questionnaire completed by the patients who reached the end of the study showed that Flugenil600 has a good and very good effectiveness in sterilizing the infection (71\%), being considered by patients to be easily administered (67.7\%) and the safety of the product being perceived as good and very good by $93.6 \%$ of them (table 4 ).

\section{Table 4}

ACCEPTABILITY (V3 - SAFETY POPULATION, $n=62$ )

\begin{tabular}{|l|l|}
\hline Characteristics & N(\%) \\
\hline Dificulty & \\
No difficulty & $42(67.7 \%)$ \\
Moderate difficulty & $13(21.0 \%)$ \\
High difficulty & $7(11.3 \%)$ \\
\hline Efficiency & \\
Very good & $13(21.0 \%)$ \\
Good & $31(50.0 \%)$ \\
Moderate & $9(14.5 \%)$ \\
No efficiency & $9(14.5 \%)$ \\
\hline Safety & \\
Very good & $26(41.9 \%)$ \\
Good & $32(51.7 \%)$ \\
Moderate & $2(3.2 \%)$ \\
No safety & $2(3.2 \%)$ \\
\hline Adverse effects & 0 \\
\hline
\end{tabular}

The therapeutic success was obtained in $42 / 50$ patients (PP population), so the efficacy of Flugenil600 is $84 \%$.

Vulvovaginal candidiasis may be acute (the first episode with typical signs and symptoms, documented by the microscopic examination and the positive cultures for Candida spp.), recurrent (at least 4 episodes in 12 months with at least 2 episodes confirmed by specific tests) or chronic (symptomatology permanently persistent, with slight improvement during menstruation, being recurrent if there is a discontinuation of the antifungal therapy, with positive specific assays for Candida) [5]. The use of boric acid in the treatment of vaginal infection with Candida spp. is documented by many studies, but they all agree that the use of boric acid is not considered the first-line therapy, especially because of its potential toxicity $[4,15,16]$.

In the medical product market, boric acid for vaginal use is presented in the form of ovules (or vaginal suppositories) containing boric acid powder $(600 \mathrm{mg})$ wrapped in a gelatine capsule [17]. It is recommended that the treatment of vaginal infection with Candida spp, using boric acid last 14 days, with a half-dose reduction in patients experiencing mucosal irritations [5]. In a study aiming to compare the intravaginal effect of $600 \mathrm{mg}$ boric acid administered daily for 14 days versus a single orally $150 \mathrm{mg}$ fluconazole dose in patients with vulvovaginal candidiasis with C. glabrata and diabetes mellitus, Ray et al. found higher healing rates in patients treated with boric acid [15]. Sobel et al. compared the efficacy of the vaginal administration of boric acid vs. flucytosine in topical administration in patients with vaginal infection documented with C. glabrata. Their study supported the superiority of flucytosin in the treatment of $\mathrm{C}$. glabrata infection, but insisted on the reduced availability in some states and the increased cost of treatment with flucytosine, thus recommending the use of boric acid as a cheap and convenient solution [10].

Marazzo et al. used a phase 2 single-blind randomized controlled trial, using a new boric acid-based product-TOL 463 (a system for vaginal administration of boric acid and EDTA (ethylenediaminetetraacetic acid)) that attacks the biofilm of fungi and bacteria involved in bacterial vaginosis, demonstrating that TOL-463 administered vaginally is effective and safe in the treatment of both vulvovaginal candidiasis and bacterial vaginosis [13]. Khameneie et al. believes that boric acid has the same efficacy as fluconazole in the treatment of vulvovaginal candidiasis [18].

After administration, boric acid is absorbed quickly into the body, its absorption being increased in situations where the skin or mucous membrane presents integrity breach. Measured daily, the serum boron level does not exceed 1 $\mu \mathrm{g} / \mathrm{mL}$ in cases of vaginal administration of $1-2$ capsules with $600 \mathrm{mg}$ of boric acid per day for 1-2 weeks (serum boron levels less than $200 \mathrm{ig} / \mathrm{ml}$ are considered safe). Boric acid is stored in the liver, kidneys and brain, $50 \%$ of the absorbed amountbeing renally excreted without being metabolised within $12 \mathrm{~h}$ after administration, the remainder being eliminated by saliva, sweating or feces [19].

The mechanism by which boric acid exerts its antifungal effect is still a matter of discussion.

In vitro, boric acid has a bacteriostatic effect on $\mathrm{C}$. albicans, requiring high doses and long incubation periods. In vivo, to dissolve $600 \mathrm{mg}$ of boric acid powder, a volume of water of at least $9 \mathrm{ml}$ is required, while solvents such as vaginal discharge have the ability to dissolve lower amounts of boric acid. For this reason, boric acid may persist for a longer period of time in the vagina (depot) with gradual dissolution. The bacteriostatic effect is also maintained in vivo, but the administration of large amounts of the substance and prolonged exposure (at least 14 days) results in the reduction of the fungus to extinction [4]. It has been speculated that boric acid exerts its antifungal effect by producing a slight acidification of the vaginal environment, the consequence of which is the destruction of the cell wall $[4,19]$; however, decreasing vaginal $\mathrm{pH}$ using other acids had no inhibitory effect on Candida [4]. On the other hand, the use of sodium borate has been shown to have an intrinsically more inhibitory effect than boric acid, probably due to the higher boron concentrations (three times higher than in boric acid) [4].

It has been found that boric acid has higher toxicity on cells in the active growth phase than in the stationary growth phase, suggesting that cell growth and proliferation mechanisms are the target of boric acid action (in fungi, boric acid leads to cytoskeletal alterations, arrest of polarized growth) [8]. Boric acid produces slow changes 
in the structure of the fungal cell membrane (decreases the level of membrane ergosterol) thus increasing the susceptibility to the destructive action of the host defence mechanisms as well as of the antifungals (azole derivatives). The reduction of the ergosterol level in the fungal membrane in the presence of boric acid is due to the interference with its aerobic synthesis mechanism, the inhibition of lanosterol demethylation in position 14 by cytochrome P450 and other enzymes [4].

Boron is a metalloid whose toxic effect consists in altering the oxidative system, damaging the DNA, and interfering with the DNA repair systems, altering the cell protein function, etc. Cells try to protect themselves against the toxic activity by developing defence mechanisms (cell boron export, intracellular storage, and lowering the influx by binding boron to proteins). Fungi present 21 genes that are responsive to boron sensitivity and 6 genes that confer resistance to boron [6]. Due to the need for a high concentration of boric acid $(600 \mathrm{mg})$ and a long period of administration (at least 14 days), the problem of fungal resistance to boric acid has arisen. The CDR1 gene for the $A B C$ transporter that functions as the adaptation efflux pump of Candida [20] is inhibited by the boric acid [4]. A member of the BMP1 transmembrane transporter family is also involved in boron cellular efflux conditioned by concentration, being considered part of the Candida environmental adaptation mechanism. Boric acid inhibits BOR1 expression while the overexpression of BOR1 protects against its cytotoxic effects [6,21].

Small amounts of boric acid are beneficial to the body, while in high doses, boric acid is toxic [8]. Intravaginal administration of boric acid is well tolerated, especially in short-term treatments, with adverse reactions (local burning sensation, aqueous leukorrhea, rash, dyspareunia, vestibulitis) reported in a small number of cases. Longterm use is not recommended due to the risk of systemic absorption and boron intoxication (gastrointestinal disorders, anemia, weakness, confusion, anorexia, alopecia, seizures, menstrual disorders, dermatitis) $[15,19]$. In pregnancy, the topical exposure to boric acid does not produce fetal abnormalities, as transcutaneous absorption is reduced through intact skin [19], while intravaginal boric acid in the first trimester of pregnancy increases the risk of fetal congenital abnormalities by 2.8 times [22].

Our study is the first of its kind developed in Romania. Unfortunately, the small number of patients included in the study and the restrictions imposed by the inclusion criteria have not allowed us to draw conclusions about the effectiveness of using boric acid ovules/suppositories in patients with mycotic vulvovaginitis and associated pathology. The result of our study recommends boric acid as an alternative to conventional drug therapy of mycotic vulvovaginitis due to the increased compliance with the treatment of the patients, the effectiveness of Candida spp infection control and the increased safety profile of administration (no adverse reactions have been reported).

\section{Conclusions}

Boric acid is an inexpensive product for clinicians who are experiencing difficulties in treating vulvovaginitis with Candida spp resistant to conventional therapy.

\section{References}

1.SOBEL JD, CHAIM W., J Clin Microbiol. 1996 Oct;34(10):2497-9. SCHALLER M, WEISSENBACHER ER. Guideline, 2015 Mar;58 Suppl 1:1-15.

2.MENDLING W, BRASCH J, CORNELY OA, EFFENDY I, FRIESE K, GINTER-HANSELMAYER G, HOF H, MAYSER P, MYLONASI, RUHNKE M, 3.GUZEL AB, KUCUKGOZ-GULEC U, AYDIN M, GUMRAL R, KALKANCI A, ILKIT M., J Obstet Gynaecol. 2013 Nov;33(8):850-6.

4. DE SETA F, SCHMIDT M, VU B, ESSMANN M, LARSEN B., J Antimicrob Chemother. $2009 \mathrm{Feb}$;63(2):325-36.

5.*** https://ww w.bashhguidelines.org/media/1187/vvc-2018-for-webconsultation.pdf.

6.ULUISIK I, KARAKAYA HC, KOC A., J Trace Elem Med Biol. 2018 Jan;45:156-162.

7.WOODS WG., Environ Health Perspect. 1994 Nov;102 Suppl 7:5-11. 8.SCHMIDT M, TRAN-NGUYEN D, CHIZEK P., J Trace Elem Med Biol. 2018Sep;49:140-145.

9.SOBEL JD, CHAIM W., Clin Infect Dis. 1997 Apr;24(4):649-5.

10. SOBEL JD, CHAIM W, NAGAPPAN V, LEAMAN D., Am J ObstetGynecol. 2003Nov;189(5):1297-300.

11.THORLEY N, ROSS J., Sex Transm Infect. 2017 Dec 9. pii: sextrans2017-053343.

12. BRITTINGHAM A, WILSON WA., Sex Transm Dis. 2014Dec;41(12):71822.

13.MARRAZZO JM, DOMBROWSKI J C, WIERZBICKI MR, PERLOWSKI C, PONTIUS A, DITHMER D, SCHWEBKE J., Clin Infect Dis. 2018 Aug 31.

14.ZERON MULLINS M, TROUTON KM., Trials. 2015 J ul 26;16:315.

15.RAY D, GOSWAMI R, BANERJEE U, DADWHAL V, GOSWAMI D, MANDAL P, SREENIVAS V, KOCHUPILLAI N., Diabetes Care. 2007 $\mathrm{Feb} ; 30(2): 312-7$.

16.SOBEL JD, SOBEL R., ExpertOpin Pharmacother. 2018 J un;19(9):971977.

17. PRUTTING SM, CERVENY JD., Infect Dis Obstet Gynecol. 1998;6(4):191-4.

18. KHAMENEIE KM, ARIANPOUR N, ROOZEGAR R, AKLAMI M, AMIRI MM., East Afr Med J. 2013 Apr;90(4):117-23.

19. LAVAZZO C, GKEGKES ID, ZARKADA IM, FALAGAS ME., J Womens Health (Larchmt). 2011 Aug;20(8):1245-55.

20. LARSEN B, ANDERSON S, BROCKMAN A, ESSMANN M, SCHMIDT M., Yeast. 2006 Aug;23(11):795-802.

21. JENNINGS ML, HOWREN TR, CUI J , WINTERS M, HANNIGAN R. Am J Physiol Cell Physiol. 2007 Jul;293(1):C468-76.

22. ACS N, BANHIDY F, PUHO E, CZEIZEL AE., Int J Gynaecol Obstet. $2006 \mathrm{Apr} ; 93(1): 55-6$.

Manuscript received:21.12.2018 